\title{
Environmental drivers of body size in North American bats
}

2

3

4
J.M. Alston ${ }^{1,2,3^{*}}$, D.A. Keinath ${ }^{4}$, C.K.R. Willis ${ }^{5}$, C.L. Lausen ${ }^{6}$, J.M. O’Keefe ${ }^{7}$, J.D. Tyburec $^{8}$, H.G. Broders ${ }^{9}$, P.R. Moosman ${ }^{10}$, T.C. Carter ${ }^{11}$, C.L. Chambers ${ }^{12}$, E.H. Gillam ${ }^{13}$, K. Geluso $^{14}$, T.J Weller ${ }^{15}$, D.W. Burles ${ }^{16}$, Q.E. Fletcher ${ }^{5}$, K.J.O. Norquay ${ }^{5}$, and J.R. Goheen ${ }^{1}$

${ }^{1}$ Department of Zoology and Physiology, University of Wyoming, Laramie, Wyoming, USA

${ }^{2}$ Program in Ecology, University of Wyoming, Laramie, Wyoming, USA

${ }^{3}$ Center for Advanced Systems Understanding (CASUS), Görlitz, Germany

${ }^{4}$ Wyoming Ecological Services Field Office, United States Fish and Wildlife Service, Cheyenne, Wyoming, USA

${ }^{5}$ Department of Biology and Centre for Forest Interdisciplinary Research, University of

Winnipeg, Winnipeg, Manitoba, Canada

${ }^{6}$ Wildlife Conservation Society Canada, Kaslo, British Columbia, Canada

${ }^{7}$ Department of Natural Resources and Environmental Sciences, University of Illinois at UrbanaChampaign, Urbana, Illinois, USA

${ }^{8}$ Bat Survey Solutions, Tucson, Arizona USA

${ }^{9}$ Department of Biology, University of Waterloo, Waterloo, Ontario, Canada

${ }^{10}$ Department of Biology, Virginia Military Institute, Lexington, Virginia, USA

${ }^{11}$ Department of Biology, Ball State University, Muncie, Indiana USA

${ }^{12}$ School of Forestry, Northern Arizona University, Flagstaff, Arizona, USA

${ }^{13}$ Department of Biological Sciences, North Dakota State University, Fargo, North Dakota, USA 
$24{ }^{14}$ Department of Biology, University of Nebraska at Kearney, Kearney, Nebraska, USA

$25{ }^{15}$ Pacific Southwest Research Station, United States Forest Service, United States Department of

26 Agriculture, Arcata, California, USA

$27{ }^{16}$ Parks Canada, Gwaii Haanas National Park Reserve and Haida Heritage Site, Queen Charlotte,

28 British Columbia, Canada

$29 *$ *Corresponding author: jalston@uwyo.edu

30

31 Statement of authorship: JA conceived the study, analyzed the data, and led writing of the

32 manuscript. JG and DK supervised the analysis and writing of the manuscript. All authors

33 collected and prepared data, made significant contributions to the drafts, and approved the

34 manuscript for publication.

35

36 
Abstract

Bergmann's Rule — which posits that larger animals live in colder areas — is thought to influence

variation in body size within species across space and time, but evidence for this claim is mixed.

We tested four competing hypotheses for spatio-temporal variation in body size within bat species during the past two decades across North America. Bayesian hierarchical models revealed that spatial variation in body mass was most strongly (and negatively) correlated with mean annual temperature, supporting the heat conservation hypothesis (historically believed to underlie Bergmann's Rule). Across time, variation in body mass was most strongly (and positively) correlated with net primary productivity, supporting the resource availability hypothesis. Climate change could influence body size in animals through both changes in mean annual temperature and in resource availability. Rapid reductions in body size associated with increasing temperatures have occurred in short-lived, fecund species, but such reductions likely transpire more slowly in longer-lived species.

Key words Bayesian hierarchical modeling, Bergmann's Rule, body size clines, Chiroptera, climate change, geographic information systems, primary productivity

\section{Introduction}

Body size influences every aspect of organismal biology, including lifespan (Lindstedt \& Calder 1981; Speakman 2005), metabolism (Brown et al. 2004; Clarke et al. 2010), movement rates (Jetz et al. 2004; Noonan et al. 2020), reproductive biology (Fenchel 1974; Blueweiss et al. 1978), and extinction risk (Brown 1995; Ripple et al. 2017). Understanding the factors that drive variation in body size is thus among the most important goals in ecology (Kaspari 2005). Bergmann's Rule 
(Bergmann 1847; Salewski \& Watt 2017), which states that animals residing in colder climates are larger than those residing in warmer climates, is a widely known macroecological pattern. Although originally and primarily applied to differences in body size between closely related species, Bergmann's Rule is often believed to extend to differences in body size within species as well (Ashton 2002; Meiri \& Dayan 2003; Blackburn \& Hawkins 2004; Watt et al. 2010; Riemer et al. 2018).

The mechanism traditionally hypothesized to underlie Bergmann's Rule is that increased size facilitates body heat conservation (hereafter, the "heat conservation hypothesis"; Bergmann 1847; Mayr 1956; Ashton 2002; Watt et al. 2010). To maintain a stable, elevated body temperature, homeotherms must operate at higher metabolic rates when faced with cooler ambient temperatures, thus losing substantial metabolic heat to the environment (McCafferty et al. 2011; Fristoe et al. 2015). The ratio between surface area and volume decreases with increasing body size, so while absolute heat loss increases with increasing body size, smaller animals require greater metabolic heat production to offset heat loss across their relatively large surface areas (Withers et al. 2016). Larger body size could therefore be an adaptation to climates with cooler average temperatures. species is mixed. Although ecologists have accumulated substantial evidence that individuals within species tend to be larger in colder climates (e.g., Smith et al. 1995; Ashton 2002; Meiri \& Dayan 2003), more recent and more comprehensive tests have failed to find consistent relationships between temperature and the body sizes of individuals within species (Riemer et al. 2018). Additionally, physiologists have questioned the validity of the heat conservation hypothesis on physiological grounds (Scholander 1955; McNab 1971; Geist 1987). In sum, and despite the 
to which variation in average temperature translates to variation in body size within species remains an open question. resulted in other hypotheses for geographical clines in body size within species that are consistent with Bergmann's Rule (Meiri et al. 2007; Salewski \& Watt 2017). For example, larger individuals exhibit acute heat stress at lower temperatures than smaller individuals, and thus experience greater risk of mortality from heat stress than smaller individuals (hereafter the 'heat mortality hypothesis'; Smith et al. 1995; Peralta-Maraver \& Rezende 2021; but see McKechnie et al. 2021).

91 This idea posits an additional (or alternative) mechanism by which animals from warmer climates are smaller than their counterparts from colder climates, and is supported in the genus Neotoma

93 (i.e., woodrats; Brown \& Lee 1969; Smith et al. 1995). A second alternative is the 'resource 94 availability hypothesis', through which increased resource availability — often correlated with 95 temperature across the globe (Gillman et al. 2015; Chu et al. 2016)—results in larger individuals and drives biogeographical patterns in body size (e.g., Rosenzweig 1968; McNab 2010; Huston \& Wolverton 2011; Yom-Tov \& Geffen 2011; Kelly et al. 2018). If true, clinal variation in body size

98 consistent with Bergmann's Rule could arise over limited geographic extents (e.g., an elevational gradient where increased precipitation increases productivity as temperature decreases), but body

100 sizes should decrease as temperatures decrease at very large (i.e., continental) spatial scales (which 101 would contradict Bergmann's Rule). Finally, a third hypothesis proposed to explain Bergmann's

102 Rule is the 'starvation resistance' (or 'seasonality') hypothesis. According to this hypothesis, large 103 body size buffers against resource scarcity driven by seasonality (Boyce 1979). Because 104 seasonality increases at higher latitudes and fasting endurance decreases at colder temperatures 105 (Lindstedt \& Boyce 1985), this dynamic may produce a size cline consistent with Bergmann's 
106 Rule. The starvation resistance hypothesis has received support from studies on songbirds (Jones

107 et al. 2005), muskrats (Ondatra zibethicus; Boyce 1978), and bobcats (Lynx rufus; Wigginton \&

108 Dobson 1999).

109 Some ecologists and evolutionary biologists have suggested that Bergmann's Rule should

110 apply over time as well as space (e.g., Smith et al. 1995; Van Buskirk et al. 2010; Merckx et al.

111 2018; Weeks et al. 2020). In other words, as temperatures fluctuate over time, the average size of

112 individuals within a species should decrease as temperatures rise and should increase as

113 temperatures fall. Although early studies of this temporal equivalent to Bergmann's Rule focused

114 on time scales of thousands of years (Smith et al. 1995), more recent studies have found that

115 changes in body size can occur over decades or even years (Van Buskirk et al. 2010; Weeks et al.

116 2020). However, and similar to the original (spatial) conceptualization of Bergmann's Rule,

117 empirical evidence for this temporal equivalent is mixed (Sheridan \& Bickford 2011; Yom-Tov \&

118 Geffen 2011; Teplitsky \& Millien 2014), perhaps because other mechanisms-analogous to

119 alternative mechanisms for Bergmann's Rule detailed above-influence shifts in body size over

120 time. For example, extreme climatic events can trigger rapid evolution of traits (Campbell-Staton

121 et al. 2017; Donihue et al. 2018), which is consistent with the heat mortality and starvation

122 resistance hypotheses. As another example, positive effects of periods of high resource availability

123 on fat reserves and growth have been documented in many taxa (e.g., Brett 1971; Boutin \& Larsen

124 1993; Altmann \& Alberts 2005; Monteith et al. 2014), and would support the resource availability

125 hypothesis. Testing these alternative hypotheses across both space and time provides a lens

126 through which to anticipate how changes in climate may affect body size in the future, as well as

127 the pace at which changes in body size may occur. 
To evaluate the mechanistic underpinnings of Bergman's Rule, we tested whether spatial and temporal variation in body mass of North American bats is best supported by the heat conservation, heat mortality, resource availability, or starvation resistance hypotheses

131 (summarized in Table 1). As with many taxa, the intraspecific formulation of Bergmann's Rule is 132 exhibited by some species of bats (e.g., Burnett 1983; Bogdanowicz 1990; Lausen et al. 2008, 133 2019), but does not appear to be the norm among the clade as a whole (Riemer et al. 2018).

134 Critically, extensive records of bat captures permit a rare opportunity to test for Bergmann's Rule 135 and evaluate its associated hypotheses while accounting for other factors (e.g., sex, age, 136 reproductive condition, and time of year) that influence body size. We compiled 17 such data sets 137 and used Bayesian hierarchical models to weigh evidence for each hypothesis across both space 138 and time for 20 species of North American bats. We expected observed patterns of variation in 139 body mass to be driven by the same process or processes across both time and space. In other 140 words, if variation in body mass across space was best explained by one of our four hypotheses, 141 we also expected variation in body mass across time to be best explained by the same hypothesis. 142 This would provide strong evidence for a consistent selective force driving variation in body size.

\section{$144 \quad 2$ Methods}

145 2.1 Data Collection

146 We compiled biometric data on bats captured throughout North America using mist nets between 1472000 and 2016 (Fig. 1). All biometric data contained information on capture location, date of 148 capture, species, sex, age class, reproductive state, and mass. Because body mass varies with 149 species, sex, age class, reproductive state, and time of year, we accounted for potential variation 150 related to these factors by calculating the mean mass for each species/sex/reproductive state 
151 combination in each month, subtracting the corresponding mean value from the mass of each

152 individual in the data set, and dividing this by the standard deviation of body mass values for that

153 species. The final data set included only data from adult bats captured between April and October,

154 for species represented by $\geq 150$ individuals and that were captured across $\geq 2.5^{\circ}$ of latitude.

156 from remotely sensed raster data sets. To test the heat conservation hypothesis across space, we 157 extracted data for each capture location from the 30 -second $(\sim 1 \mathrm{~km})$ resolution version of the

158 WorldClim 2.1 mean temperature data set (mean annual temperature, 1970-2000; Fick \& Hijmans

159 2017). We centered mean annual temperatures in our data set at zero by subtracting the mean

160 annual temperature across all capture locations. To test the heat conservation hypothesis across

161 time, we extracted data for each capture location from the DAYMET daily climate summaries 1-

$162 \mathrm{~km}$ resolution data set (Thornton et al. 2020) using the 'daymetr' package (version 1.4; Hufkens

163 et al. 2018). We used those data to calculate the midpoint of low and high temperatures across all

164 days from 1 April until the date each bat was captured, and then subtracted the average of this

165 value at the capture location during our study period (2000-2016) to obtain a final centered metric

166 of year-to-year differences in mean temperatures. This represents roughly the period in which a

167 bat would be active in a given year (dates before 1 April are likely to be spent in hibernation or in 168 winter ranges).

To test the heat mortality hypothesis across space, we extracted data for each capture

170 location from the DAYMET daily climate summaries $1-\mathrm{km}$ resolution data set (Thornton et al.

171 2020) and used those data to calculate the maximum temperature at each capture location in each

172 year between 1980 and 2010 (the earliest 30-year period available). We then calculated the mean 173 annual maximum temperature across this 30-year period at each site and subtracted the mean 
174 annual maximum temperature across all sites to obtain a final centered metric of long-term

175 maximum annual temperatures. To test the heat mortality hypothesis across time, we extracted

176 data for each capture location from the DAYMET daily climate summaries 1-km resolution data

177 set (Thornton et al. 2020). We calculated the maximum temperature in the prior 365 days for each

178 capture event, then subtracted the long-term average for this value at the site of capture to calculate

179 a final centered metric of year-to-year differences in maximum temperatures.

To test the resource availability hypothesis across space, we extracted data for each capture

181 location from the 0.1-degree $(\sim 10 \mathrm{~km})$ resolution version of the MODIS monthly net primary

182 productivity data set (Stockli 2020). Primary productivity is positively correlated with insect

183 biomass across both space (Borer et al. 2012; Lind et al. 2017) and time (Bell 1985; Frith \& Frith

184 1985), and summer precipitation - another common proxy for resource availability — is positively

185 correlated with annual survival in little brown bats (Myotis lucifugus; Frick et al. 2010). We

186 averaged monthly net primary productivity across months during the active season for bats (April-

187 October) for all available years (2000-2016), then divided by the mean value across all sites to

188 obtain a final metric centered at one. To test the resource availability hypothesis across time, we

189 extracted data from the same rasters and averaged net primary productivity for months preceding

190 the date a bat was captured (in the year of capture, inclusive of the month of capture, starting in

191 April), then divided by the average of this value at the site of capture for the entire time period.

192 To test the starvation resistance hypothesis across space, we extracted data for each capture

193 location from the 30-second $(\sim 1 \mathrm{~km})$ resolution version of the WorldClim 2.1 minimum

194 temperature data set (mean minimum temperature, 1970-2000; Fick and Hijmans 2017). To

195 estimate the severity of resource limitation in the period in which bats are most resource-limited,

196 we averaged minimum temperatures across the months of September, October, April, and May, 
197 which roughly represent night-time temperatures during the times of year when bats tend to be most energetically vulnerable. Regardless of whether they hibernate or migrate for the winter, bats

199 at temperate latitudes must gain a substantial amount of weight in the autumn (Kunz et al. 1998;

200 Lacki et al. 2015; Guglielmo 2018; Cheng et al. 2019; Sommers et al. 2019), and they tend to be

201 energetically stressed in the early spring before insects become abundant (Arlettaz et al. 2001;

202 Encarnação et al. 2004; Jonasson \& Guglielmo 2019). Daily minimum temperatures during

203 autumn and spring thus represent a biologically informed proxy for resource limitation. We

204 centered mean minimum spring and autumn temperatures in our data set at zero by subtracting the

205 mean minimum spring and autumn temperature across all capture locations. To test the starvation

206 resistance hypothesis across time, we extracted data from the DAYMET daily climate summaries

207 1-km resolution data set (Thornton et al. 2020). We averaged the minimum daily temperatures for

208 the spring (April and May) and autumn (September and October) preceding the date on which a

209 bat was caught, and subtracted the average value at the site of capture during our study period.

\subsection{Statistical Analysis}

216 species (i.e., 20 models in total; Fig. A1) to quantify the effects on body mass of the

217 environmental predictors detailed above. Each model included 3 chains that were run for 12,000

218 iterations (2,000 iterations of warm-up and 10,000 iterations of sampling). We assessed chain

219 convergence using the Gelman-Rubin diagnostic $(\hat{\mathrm{R}})$ and precision of parameter estimation using 
220 effective sample size. $\hat{\mathrm{R}}<1.01$ and effective sample sizes $>10,000$ represent acceptable

221 convergence and parameter precision (Gelman et al. 2013; Kruschke 2015). We used leave-one-

222 out cross-validation to check model fit using the R packages 'loo' (version 2.3.1; Vehtari et al.

223 2017), and 'bayesplot' (version 1.7.2; Gabry et al. 2019) to visually assess the cross-validated

224 probability integral transform.

\section{Results}

227 The final data set contained 31,303 individuals of 20 species captured at 1,190 locations (Fig. 1;

228 Table A1). Most species were larger at higher latitudes, but body size remained relatively

229 constant over our study period (Fig. A2). Significant spatial and temporal variation existed

230 among all predictor variables, enabling detection of meaningful relationships between body mass

231 and predictor variables (Fig. A3).

232

\section{Spatial Variation in Body Mass}

234 Spatial variation in body mass most strongly supported the heat conservation hypothesis, with 235 most species exhibiting greater body mass in areas with colder mean annual temperatures (Fig. 236 2A). For 15 of 20 species, body mass declined with increasing mean annual temperature (i.e., $\beta<$ 237 0), and the probability that the coefficient was less than zero was $>95 \%$ for 6 of these species 238 (Myotis lucifugus, Eptesicus fuscus, Lasionycteris noctivagans, M. ciliolabrum, M. evotis, and

239 Parastrellus hesperus). Most species exhibited minimal variation in body mass with respect to 240 maximum temperature (Fig. 2B), primary productivity (Fig. 2C), and spring/autumn temperatures 241 (Fig. 2D), suggesting a lack of support for the heat mortality, resource availability, and starvation 242 resistance hypotheses, respectively. For these three hypotheses, coefficients were relatively evenly 
distributed around 0;90\% credible intervals overlapped 0 in most cases, and credible intervals that

244 did not overlap zero were distributed relatively evenly around zero.

\section{Temporal (Interannual) Variation in Body Mass}

247 Temporal variation in body mass most strongly supported the resource availability hypothesis,

248 with most species exhibiting greater body mass during years in which net primary productivity

249 was higher (Fig. 3C). For 14 of 20 species, body mass increased with increasing net primary

250 productivity (i.e., $\beta>0$ ), and the probability that the coefficient was above zero was $>95 \%$ for 7

251 of these species (Myotis lucifugus, Eptesicus fuscus, M. ciliolabrum, M. californicus, Perimyotis

252 subflavans, $M$. sodalis, M. leibii). Most species exhibited little variation in body mass with respect

253 to year-to-year differences in mean annual temperatures (Fig. 3A), maximum temperatures (Fig.

254 3B), or spring/autumn temperatures (Fig. 3D), suggesting a lack of support for the heat

255 conservation, heat mortality, and starvation resistance hypotheses, respectively. For these

256 hypotheses, coefficients were relatively evenly distributed around $0,90 \%$ credible intervals

257 overlapped 0 in most cases, and credible intervals that did not overlap zero were relatively evenly

258 distributed around zero or were distributed in the direction opposite most coefficients.

2604 Discussion

261 Although intraspecific clines in body size have received attention for nearly two centuries

262 (Bergmann 1847; Watt et al. 2010), recent studies have cast doubt on both their prevalence and

263 the generality of the mechanisms underlying them (e.g., Meiri et al. 2007; Muñoz et al. 2014;

264 Freeman 2017; Riemer et al. 2018). We used North American bats as a model system to test four

265 competing hypotheses (Table 1) for intraspecific variation in body mass consistent with 
Bergmann's Rule, a well-known macroecological pattern. Further, because recent evidence suggests that the mechanisms underlying such geographical clines could be causing rapid evolutionary change in body size (e.g., Van Buskirk et al. 2010; Merckx et al. 2018; Weeks et al. 2020), we also tested the ability of these four hypotheses to describe interannual variation in body mass. Although no hypothesis described variation in body mass across every species, spatial

271 variation in body mass of bats was most consistently correlated with mean annual temperature 272 (supporting the heat conservation hypothesis, originally assumed to underlie Bergmann's Rule), 273 and temporal variation in body mass was most consistently correlated with net primary 274 productivity (supporting the resource availability hypothesis). In tandem, our results highlight that 275 both spatial and temporal patterns of variation in body size have an energetic basis, but via two 276 distinct pathways: spatial variation in body size is driven by energy loss to the environment in the 277 form of heat, and temporal variation in body size is driven by energy gain from abundant food.

Across North America, body mass of bats was most strongly correlated with mean annual temperature, matching the traditional hypothesis - the heat conservation hypothesis-for Bergmann's Rule (Bergmann 1847; Mayr 1956). However, this mechanism had little influence on

281 temporal variation in body size, perhaps because selective pressure via size-dependent differences 282 in energy expenditure could take considerable time to manifest. Compared to the heat mortality 283 and starvation resistance hypotheses - which assume punctuated bouts of high mortality driven by 284 extreme heat and severe resource scarcity, respectively - the heat conservation hypothesis posits 285 more gradual selection on body size. Differences in survival and reproduction between small 286 individuals and large individuals may therefore fail to manifest in measurable population-level 287 variation in body size, even after unusually warm or cold years. Only after climate departs from 288 historical norms over many generations should body size change at the population level. 
Recent research has cast doubt on the assumption that the heat conservation hypothesis underlies Bergmann's Rule (Riemer et al. 2018). Using museum specimens of a wide array of endotherms (including bats) collected across the globe, Riemer et al. (2018) found that intraspecific variation in body mass did not vary with mean annual temperature. Our results contradict this finding, likely because we were able to account for confounding sources of variation

294 in body mass (e.g., sex, reproductive status, time of year, resource availability). A diverse array of factors contributes to variation in body mass, and their cumulative influence could swamp variation driven by mean annual temperature (Jones et al. 2005; Meiri et al. 2007; Nunes et al. 2017). Given this challenge, carefully accounting for potential confounding factors is necessary

298 for clarifying the extent to which mean annual temperature drives variation in body size within 299 species. Additionally, our threshold for minimum sample sizes was higher than the threshold used by Riemer et al. ( $n=150$ vs. $n=30$ ), and our ability to detect strong evidence for our best301 supported hypotheses was positively correlated with sample size. Of the coefficients with $>95 \%$ 302 probability of supporting the best-supported hypotheses, 5 of 6 coefficients that supported the heat conservation hypothesis across space and 4 of 7 coefficients that supported the resource 304 availability process across time were located in species with $n>1,000$ individuals. Given the degree of variation inherent in such broadly collected data, compiling very large data sets $(n>$ 306 1,000) may be necessary to detect Bergmann’s Rule within species in wild populations. That resource availability might drive body mass variation temporally but not spatially is

308 consistent with predictions of the ideal free distribution model of resource selection (Fretwell \& 309 Lucas 1969; Royama 1970) and the "more-individual hypothesis" for species-energy relationships 310 (Wright 1983; Srivastava \& Lawton 1998; Storch et al. 2018). If individuals within a species are 311 distributed in an ideal free manner, populations should be denser in areas with greater resource 
312 availability, such that per capita resource availability is roughly equivalent over their geographic

313 range. In this scenario, individuals should not necessarily be appreciably larger or heavier in

314 resource-rich areas than in resource-poor areas, but populations should be denser or sparser,

315 respectively. In other words, additional energy is converted into additional individuals, rather than

316 larger individuals. However, if resource availability changes from year to year, this equilibrium

317 can be disrupted, leading to temporary situations in which per capita resource availability is higher

318 in some areas than others until population densities reach a steady state of resource availability. In

319 this scenario, individuals would likely be larger or heavier in (temporarily) resource-rich areas

320 than in (temporarily) resource-poor areas, and this temporal variation in body mass would be

321 driven more by changes in nutritional condition (i.e., fat reserves and muscle mass) than by

322 differences in body size arising from directional selection. This dynamic is likely to be particularly

323 pronounced in long-lived species that produce few offspring (such as bats; Wilkinson \& South

324 2002), because population density cannot rapidly track changes in resource availability via

325 increases in recruitment.

Importantly, our analyses indicate that the processes that drive spatial patterns in body size

327 might not produce equivalent temporal patterns over ecological time scales. Variation in body size

328 occurs both temporally and spatially, but the underlying processes are likely distinct and could

329 manifest over markedly different timescales. Motivated by patterns of spatial variation in body

330 size, many biologists have attempted to quantify analogous patterns through time, typically over

331 the course of years or decades (e.g., Sheridan \& Bickford 2011; Caruso et al. 2014; Teplitsky \&

332 Millien 2014). However, spatial patterns could take centuries or millennia to arise, even when they

333 are relatively clear-cut (and spatial patterns in body size are rarely so). This is especially true for 
334 long-lived species, for which the pace of change is likely to be slower than for short-lived, more 335 fecund species.

Climate change will likely induce changes in body size for animals, but such changes may be more complex than has been appreciated. Over the nearly 2 decades that we collected data, the primary driver of short-term (annual) variation in body size was resource availability. Increases in mean annual temperatures could make many ecosystems more productive for a longer portion of the year, but changes in precipitation can both accentuate and dampen such shifts in productivity (Chu et al. 2016; La Pierre et al. 2016). Any changes in body size driven by climate change will therefore depend on the extent to which mean annual temperature, amount of precipitation, and timing of precipitation are altered for a given area. Moreover, and because net primary productivity

344 does not meaningfully influence body size across space, any such changes are likely to be transient, renormalizing over time if humans eventually curb greenhouse gas emissions. compelling evidence of rapid changes in body size due to climate change comes from songbirds (e.g., Van Buskirk et al. 2010; Weeks et al. 2020), which are shorter lived and more fecund than bats. Controlling for size, bats live on average 3.5 times longer than other placental mammals (Wilkinson \& South 2002). Individuals with lifespans > 30 years have been documented in several 351 species, and bats typically produce only 1-2 offspring per year (Wilkinson \& South 2002; Barclay 352 \& Harder 2003). Because pace of life is positively correlated with the pace of evolution (i.e., 353 smaller, more fecund species tend to evolve more rapidly; Martin \& Palumbi 1993; Gillooly et al. 2005; Nabholz et al. 2008), the processes that lead to spatial variation in body size should arise faster over time in short-lived species than in long-lived species. Additional studies that enable 356 direct comparisons of the pace of body size change across taxa with different life history strategies 
will increase ecologists' understanding of the extent and pace of changes in body size caused by climate change.

While recent evidence indicates that higher temperatures caused by climate change are inducing rapid evolution in body size in some species (Van Buskirk et al. 2010; Gardner et al. 2011; Weeks et al. 2020), we found no evidence that this is occurring in bats. Spatial variation in

362 body mass of North American bats is consistent with the heat conservation hypothesis for 363 Bergmann's Rule, but the heat conservation hypothesis does not explain variation in body size over time. Instead, temporal variation in body mass over the past two decades appears to be driven largely by year-to-year changes in resource availability. For bats and other long-lived species, temperature-induced reductions in body size could take substantially longer to manifest than for short-lived, more fecund species, and will be obscured by variation in resource availability.

\section{Acknowledgements}

Many thanks to J.A. Rick for help with analytical code and helpful comments on early versions

371 of this manuscript. We thank D. Bachen, D. Blouin, S. Bradley, M.-A. Collis, K. Cross, N.

372 Dorville, H. Gates, K.N. Geluso, J. Huebschman, K. Jonasson, D. Nagorson, T. Snow, D. Sparks,

373 H. Thomas, J. Veilleux, B. Walters, J. Whitaker, many Utah Division of Wildlife biologists and

374 technicians, and many others for their work to collect and compile data used for this project. We

375 also thank the Alberta Conservation Association, Arizona Biomedical Research Commission,

376 Arizona Game and Fish Department Heritage Fund, Arizona Game and Fish Department State

377 Wildlife Grant, Bat Conservation International, British Columbia Hydro and Power Authority,

378 British Columbia Ministry of Environment, British Columbia Fish and Wildlife Compensation

379 Program, Habitat Conservation Trust Foundation, Columbia Basin Trust, Indiana Department of 
Natural Resources, Montana Natural Heritage Program Core Fund, National Science Foundation,

381 Natural Sciences and Engineering Research Council of Canada, Nebraska Game and Parks

382 Commission, North Dakota Department of Agriculture, North Dakota Game and Fish

383 Department, Northern Arizona University, Parks Canada, State of Arizona Technology and

384 Research Initiative Fund, University of Wyoming College of Arts and Sciences, University of

385 Wyoming Department of Zoology and Physiology, US Bureau of Land Management, US

386 Department of Agriculture Wildlife Services, US Department of Agriculture Natural Resources

387 Conservation Service, US Department of Defense Legacy Resource Management Program, US

388 Fish and Wildlife Service, US Forest Service, US Forest Service Rocky Mountain Research

389 Station, US Forest Service Southern Research Station, US Geological Survey, US National Park

390 Service, Utah Division of Wildlife, Utah Endangered Species Mitigation Fund, Virginia

391 Department of Wildlife Resources, and funders of Wildlife Conservation Society Canada's

392 Western Canada Bat Conservation Program (wcsbats.ca) for funding that made this project

393 possible. This paper includes data from the Hardwood Ecosystem Experiment, a partnership of

394 the Indiana Department of Natural Resources, Purdue University, Ball State University, Indiana

395 State University, Drake University, and The Nature Conservancy. This work was partly funded

396 by the Center for Advanced Systems Understanding (CASUS) which is financed by Germany's

397 Federal Ministry of Education and Research (BMBF) and by the Saxon Ministry for Science,

398 Culture and Tourism (SMWK) with tax funds on the basis of the budget approved by the Saxon

399 State Parliament.

\section{References}


Altmann, J. \& Alberts, S.C. (2005). Growth rates in a wild primate population: ecological influences and maternal effects. Behav. Ecol. Sociobiol., 57, 490-501.

Arlettaz, R., Christe, P., Lugon, A., Perrin, N. \& Vogel, P. (2001). Food availability dictates the timing of parturition in insectivorous mouse-eared bats. Oikos, 95, 105-111.

Ashton, K.G. (2002). Patterns of within-species body size variation of birds: strong evidence for Bergmann's rule. Glob. Ecol. Biogeogr., 11, 505-523.

Barclay, R.M.R. \& Harder, L.D. (2003). Life histories of bats: life in the slow lane. In: Bat Ecology (eds. Kunz, T.H. \& Fenton, M.B.). University of Chicago Press, Chicago, IL, USA, pp. 209-253.

Bell, H.L. (1985). Seasonal variation and the effects of drought on the abundance of arthropods in savanna woodland on the Northern Tablelands of New South Wales. Aust. J. Ecol., 10, $207-221$.

Bergmann, C. (1847). Ueber die Verhältnisse der Wärmeökonomie der Thiere zu ihrer Grösse. Göttinger Studien, 1, 595-708.

Blackburn, T.M. \& Hawkins, B.A. (2004). Bergmann's rule and the mammal fauna of northern North America. Ecography, 27, 715-724.

Blueweiss, L., Fox, H., Kudzma, V., Nakashima, D., Peters, R. \& Sams, S. (1978). Relationships between body size and some life history parameters. Oecologia, 37, 257-272.

Bogdanowicz, W. (1990). Geographic variation and taxonomy of Daubenton's bat, Myotis daubentoni in Europe. J. Mammal., 71, 205-218.

Borer, E.T., Seabloom, E.W. \& Tilman, D. (2012). Plant diversity controls arthropod biomass and temporal stability. Ecol. Lett., 15, 1457-1464. 
424 Boutin, S. \& Larsen, K.W. (1993). Does food availability affect growth and survival of males and females differently in a promiscuous small mammal, Tamiasciurus hudsonicus? J. Anim. Ecol., 62, 364-370.

Boyce, M.S. (1978). Climatic variability and body size variation in the muskrats (Ondatra zibethicus) of North America. Oecologia, 36, 1-19.

Boyce, M.S. (1979). Seasonality and patterns of natural selection for life histories. Am. Nat., 114,

Brett, J.R. (1971). Energetic responses of salmon to temperature. A study of some thermal $569-583$. relations in the physiology and freshwater ecology of sockeye salmon (Oncorhynchus nerka). Am. Zool., 11, 99-113.

Brown, J.H. (1995). Macroecology. University of Chicago Press, Chicago, IL, USA.

Brown, J.H., Gillooly, J.F., Allen, A.P., Savage, V.M. \& West, G.B. (2004). Toward a metabolic theory of ecology. Ecology, 1771-1789.

Brown, J.H. \& Lee, A.K. (1969). Bergmann's rule and climatic adaptation in woodrats (Neotoma). Evolution, 23, 329-338.

Bürkner, P.-C. (2017). brms: an R package for Bayesian multilevel models using Stan. J. Stat. Softw., 80, 1-28.

Burnett, C.D. (1983). Geographic and climatic correlates of morphological variation in Eptesicus fuscus. J. Mammal., 64, 437-444.

Campbell-Staton, S.C., Cheviron, Z.A., Rochette, N., Catchen, J., Losos, J.B. \& Edwards, S.V. (2017). Winter storms drive rapid phenotypic, regulatory, and genomic shifts in the green anole lizard. Science, 357, 495-498. 
Carpenter, B., Gelman, A., Hoffman, M.D., Lee, D., Goodrich, B., Betancourt, M., et al. (2017). Stan: a probabilistic programming language. J. Stat. Softw., 76.

Caruso, N.M., Sears, M.W., Adams, D.C. \& Lips, K.R. (2014). Widespread rapid reductions in body size of adult salamanders in response to climate change. Glob. Change Biol., 20, $1751-1759$.

Cheng, T.L., Gerson, A., Moore, M.S., Reichard, J.D., DeSimone, J., Willis, C.K.R., et al. (2019). Higher fat stores contribute to persistence of little brown bat populations with white-nose syndrome. J. Anim. Ecol., 88, 591-600.

Chu, C., Bartlett, M., Wang, Y., He, F., Weiner, J., Chave, J., et al. (2016). Does climate directly influence NPP globally? Glob. Change Biol., 22, 12-24.

Clarke, A., Rothery, P. \& Isaac, N.J.B. (2010). Scaling of basal metabolic rate with body mass and temperature in mammals. J. Anim. Ecol., 79, 610-619.

Donihue, C.M., Herrel, A., Fabre, A.-C., Kamath, A., Geneva, A.J., Schoener, T.W., et al. (2018). Hurricane-induced selection on the morphology of an island lizard. Nature, 560, 88-91.

Encarnação, J.A., Dietz, M., Kierdorf, U. \& Wolters, V. (2004). Body mass changes in male Daubenton's bats Myotis daubentonii (Chiroptera, Vespertilionidae) during the seasonal activity period. Mammalia, 68, 291-297.

Fenchel, T. (1974). Intrinsic rate of natural increase: the relationship with body size. Oecologia, $14,317-326$.

Fick, S.E. \& Hijmans, R.J. (2017). WorldClim 2: new 1-km spatial resolution climate surfaces for global land areas. Int. J. Climatol., 37, 4302-4315. 
Freeman, B.G. (2017). Little evidence for Bergmann's rule body size clines in passerines along tropical elevational gradients. J. Biogeogr., 44, 502-510.

Fretwell, S.D. \& Lucas, H.L. (1969). On territorial behavior and other factors influencing habitat distribution in birds. Acta Biotheor., 19, 16-36.

Frick, W.F., Reynolds, D.S. \& Kunz, T.H. (2010). Influence of climate and reproductive timing on demography of little brown myotis Myotis lucifugus. J. Anim. Ecol., 79, 128-136.

Fristoe, T.S., Burger, J.R., Balk, M.A., Khaliq, I., Hof, C. \& Brown, J.H. (2015). Metabolic heat production and thermal conductance are mass-independent adaptations to thermal environment in birds and mammals. Proc. Natl. Acad. Sci. U.S.A., 112, 15934-15939.

Frith, C.B. \& Frith, D.W. (1985). Seasonality of insect abundance in an Australian upland tropical rainforest. Aust. J. Ecol., 10, 237-248.

Gabry, J., Simpson, D., Vehtari, A., Betancourt, M. \& Gelman, A. (2019). Visualization in Bayesian workflow. J. Royal Stat. Soc. A, 182, 389-402.

Gardner, J.L., Peters, A., Kearney, M.R., Joseph, L. \& Heinsohn, R. (2011). Declining body size: a third universal response to warming? Trends Ecol. Evol., 26, 285-291.

Geist, V. (1987). Bergmann's rule is invalid. Can. J. Zool., 65, 1035-1038.

Gelman, A., Carlin, J.B., Stern, H.S., Dunson, D.B., Vehtari, A. \& Rubin, D.B. (2013). Bayesian data analysis. Third. CRC Press, Boca Raton, FL, USA.

Gillman, L.N., Wright, S.D., Cusens, J., McBride, P.D., Malhi, Y. \& Whittaker, R.J. (2015). Latitude, productivity and species richness. Glob. Ecol. Biogeogr., 24, 107-117.

Gillooly, J.F., Allen, A.P., West, G.B. \& Brown, J.H. (2005). The rate of DNA evolution: effects of body size and temperature on the molecular clock. Proc. Natl. Acad. Sci. U.S.A., 102, $140-145$. 
Guglielmo, C.G. (2018). Obese super athletes: fat-fueled migration in birds and bats. J. Exp. Biol., 221.

Hufkens, K., Basler, D., Milliman, T., Melaas, E.K. \& Richardson, A.D. (2018). An integrated phenology modelling framework in r. Meth. Ecol. Evol., 9, 1276-1285.

Huston, M.A. \& Wolverton, S. (2011). Regulation of animal size by eNPP, Bergmann's rule and related phenomena. Ecol. Monogr., 81, 349-405.

Jetz, W., Carbone, C., Fulford, J. \& Brown, J.H. (2004). The scaling of animal space use. Science, 306, 266-268.

Jonasson, K.A. \& Guglielmo, C.G. (2019). Evidence for spring stopover refuelling in migrating silver-haired bats (Lasionycteris noctivagans). Can. J. Zool., 97, 961-970.

Jones, J., Gibb, C.E., Millard, S.C., Barg, J.J., Girvan, M.K., Veit, M.L., et al. (2005). Multiple selection pressures generate adherence to Bergmann's rule in a Neotropical migratory songbird. J. Biogeogr., 32, 1827-1833.

Kaspari, M. (2005). Global energy gradients and size in colonial organisms: worker mass and worker number in ant colonies. Proc. Natl. Acad. Sci. U.S.A., 102, 5079-5083.

Kelly, R.M., Friedman, R. \& Santana, S.E. (2018). Primary productivity explains size variation across the pallid bat's western geographic range. Funct. Ecol., 32, 1520-1530.

Kruschke, J. (2015). Doing Bayesian analysis. Second. Academic Press, Waltham, MA, USA.

Kunz, T.H., Wrazen, J.A. \& Burnett, C.D. (1998). Changes in body mass and fat reserves in prehibernating little brown bats (Myotis lucifugus). Écoscience, 5, 8-17.

La Pierre, K.J., Blumenthal, D.M., Brown, C.S., Klein, J.A. \& Smith, M.D. (2016). Drivers of variation in aboveground net primary productivity and plant community composition differ across a broad precipitation gradient. Ecosystems, 19, 521-533. 
514 Lacki, M.J., Dodd, L.E., Toomey, R.S., Thomas, S.C., Couch, Z.L. \& Nichols, B.S. (2015). Temporal changes in body mass and body condition of cave-hibernating bats during staging and swarming. J. Fish Wildl. Manage., 6, 360-370.

Lausen, C.L., Delisle, I., Barclay, R.M.R. \& Strobeck, C. (2008). Beyond mtDNA: nuclear gene flow suggests taxonomic oversplitting in the little brown bat (Myotis lucifugus). Can. J. Zool., 86, 700-713. genetics reveal Myotis keenii (Keen's myotis) and Myotis evotis (long-eared myotis) to be

Lind, E.M., Pierre, K.J.L., Seabloom, E.W., Alberti, J., Iribarne, O., Firn, J., et al. (2017). Increased grassland arthropod production with mammalian herbivory and eutrophication:

Lindstedt, S.L. \& Boyce, M.S. (1985). Seasonality, fasting endurance, and body size in mammals. Am. Nat., 125, 873-878.

Lindstedt, S.L. \& Calder, W.A. (1981). Body size, physiological time, and longevity of homeothermic animals. Q. Rev. Biol., 56, 1-16.

Martin, A.P. \& Palumbi, S.R. (1993). Body size, metabolic rate, generation time, and the

532 Mayr, E. (1956). Geographical character gradients and climatic adaptation. Evolution, 10, 105108. 
thermography with biophysical modelling. Comp. Biochem. Physiol. Part A Mol. Integr. Physiol., 158, 337-345.

McKechnie, A.E., Gerson, A.R. \& Wolf, B.O. (2021). Thermoregulation in desert birds: scaling and phylogenetic variation in heat tolerance and evaporative cooling. J. Exp. Biol., 224.

McNab, B.K. (1971). On the ecological significance of Bergmann's Rule. Ecology, 52, 845-854.

McNab, B.K. (2010). Geographic and temporal correlations of mammalian size reconsidered: a resource rule. Oecologia, 164, 13-23.

Meiri, S. \& Dayan, T. (2003). On the validity of Bergmann's rule. J. Biogeogr., 30, 331-351.

Meiri, S., Yom-Tov, Y. \& Geffen, E. (2007). What determines conformity to Bergmann's rule? Glob. Ecol. Biogeogr., 16, 788-794.

Merckx, T., Souffreau, C., Kaiser, A., Baardsen, L.F., Backeljau, T., Bonte, D., et al. (2018). Body-size shifts in aquatic and terrestrial urban communities. Nature, 558, 113-116.

Monteith, K.L., Bleich, V.C., Stephenson, T.R., Pierce, B.M., Conner, M.M., Kie, J.G., et al. (2014). Life-history characteristics of mule deer: effects of nutrition in a variable environment. Wildl. Monogr., 186, 1-62.

Muñoz, M.M., Wegener, J.E. \& Algar, A.C. (2014). Untangling intra- and interspecific effects on body size clines reveals divergent processes structuring convergent patterns in Anolis lizards. Am. Nat., 184, 636-646.

Nabholz, B., Glémin, S. \& Galtier, N. (2008). Strong variations of mitochondrial mutation rate across mammals - the longevity hypothesis. Mol. Biol. Evol., 25, 120-130.

Noonan, M.J., Fleming, C.H., Tucker, M.A., Kays, R., Harrison, A.-L., Crofoot, M.C., et al. (2020). Effects of body size on estimation of mammalian area requirements. Conserv. Biol., 34, 1017-1028. 
Nunes, G.T., Mancini, P.L. \& Bugoni, L. (2017). When Bergmann's rule fails: evidence of environmental selection pressures shaping phenotypic diversification in a widespread seabird. Ecography, 40, 365-375.

Peralta-Maraver, I. \& Rezende, E.L. (2021). Heat tolerance in ectotherms scales predictably with body size. Nat. Clim. Change, 11, 58-63.

R Core Team. (2020). R: a language and environment for statistical computing. R Foundation for Statistical Computing, Vienna, Austria.

Riemer, K., Guralnick, R.P. \& White, E.P. (2018). No general relationship between mass and temperature in endothermic species. eLife, 7, e27166.

Ripple, W.J., Wolf, C., Newsome, T.M., Hoffman, M., Wirsing, A.J. \& McCauley, D.J. (2017). Extinction risk is most acute for the world's largest and smallest vertebrates. Proc. Natl. Acad. Sci. U.S.A., 114, 10678-10683.

Rosenzweig, M.L. (1968). The strategy of body size in mammalian carnivores. Am. Midl. Nat., $80,299-315$.

Royama, T. (1970). Evolutionary significance of predators' response to local differences in prey density: a theoretical study. Proc. Adv. Study Inst. Dynamic Numbers Popul., 344-357.

Salewski, V. \& Watt, C. (2017). Bergmann's rule: a biophysiological rule examined in birds. Oikos, 126, 161-172.

Scholander, P.F. (1955). Evolution of climatic adaptation in homeotherms. Evolution, 9, 15-26.

Sheridan, J.A. \& Bickford, D. (2011). Shrinking body size as an ecological response to climate change. Nat. Clim. Change, 1, 401-406.

Smith, F.A., Betancourt, J.L. \& Brown, J.H. (1995). Evolution of body size in the woodrat over the past 25,000 years of climate change. Science, 270, 2012-2014. 
Sommers, A.S., Rogers, E.J. \& McGuire, L.P. (2019). Migration and reproduction are associated with similar degrees of phenotypic flexibility in an insectivorous bat. Oecologia, 190, $747-755$.

Speakman, J.R. (2005). Body size, energy metabolism and lifespan. J. Exp. Biol., 208, 17171730.

Srivastava, D.S. \& Lawton, J.H. (1998). Why more productive sites have more species: an experimental test of theory using tree-hole communities. Am. Nat., 152, 510-529.

Stockli, R. (2020). Net Primary Productivity (1 month - Terra/MODIS). Available at: https://neo.sci.gsfc.nasa.gov/view.php?datasetId=MOD17A2_M_PSN. Last accessed 18 September 2020 .

Storch, D., Bohdalková, E. \& Okie, J. (2018). The more-individuals hypothesis revisited: the role of community abundance in species richness regulation and the productivity-diversity relationship. Ecol. Lett., 21, 920-937.

Teplitsky, C. \& Millien, V. (2014). Climate warming and Bergmann's rule through time: is there any evidence? Evol. Appl., 7, 156-168.

Thornton, M.M., Thornton, P.E., Wei, Y., Mayer, B.W., Cook, R.B. \& Vose, R.S. (2020). Daymet: monthly climate summaries for a 1-km grid for North America. ORNL DAAC, Oak Ridge, TN, USA.

Van Buskirk, J., Mulvihill, R.S. \& Leberman, R.C. (2010). Declining body sizes in North American birds associated with climate change. Oikos, 119, 1047-1055.

Vehtari, A., Gelman, A. \& Gabry, J. (2017). Practical Bayesian model evaluation using leaveone-out cross-validation and WAIC. Stat. Comput., 27, 1413-1432. 
604 Watt, C., Mitchell, S. \& Salewski, V. (2010). Bergmann's rule; a concept cluster? Oikos, 119,

605 89-100.

606 Weeks, B.C., Willard, D.E., Zimova, M., Ellis, A.A., Witynski, M.L., Hennen, M., et al. (2020).

607 Shared morphological consequences of global warming in North American migratory

$608 \quad$ birds. Ecol. Lett., 23, 316-325.

609 Wigginton, J.D. \& Dobson, F.S. (1999). Environmental influences on geographic variation in body size of western bobcats. Can. J. Zool., 77, 802-813.

611 Wilkinson, G.S. \& South, J.M. (2002). Life history, ecology and longevity in bats. Aging Cell, 1, $124-131$.

613 Withers, P.C., Cooper, C.E., Maloney, S.K., Bozinovic, F. \& Cruz-Neto, A.P. (2016). Ecological and environmental physiology of mammals. 1st edn. Oxford University Press, Oxford, U.K.

616 Wright, D.H. (1983). Species-energy theory: an extension of species-area theory. Oikos, 41, 496-506.

618 Yom-Tov, Y.\& Geffen, E. (2011). Recent spatial and temporal changes in body size of terrestrial vertebrates: probable causes and pitfalls. Biol. Rev., 86, 531-541. 


\begin{tabular}{|c|c|c|c|c|}
\hline Hypothesis Name & Spatial Hypothesis & Spatial Proxy Data & Temporal Hypothesis & Temporal Proxy Data \\
\hline Heat Conservation & $\begin{array}{l}\text { Because larger body size } \\
\text { increases an individual's ability } \\
\text { to conserve body heat, } \\
\text { individuals will be larger in } \\
\text { areas where average } \\
\text { temperatures are lower. }\end{array}$ & $\begin{array}{l}\text { Mean annual } \\
\text { temperature (1970- } \\
\text { 2000; WorldClim; Fick } \\
\text { and Hijmans 2017) }\end{array}$ & $\begin{array}{l}\text { Because larger body size } \\
\text { increases an individual's ability } \\
\text { to conserve body heat, } \\
\text { individuals will be larger after } \\
\text { years in which average } \\
\text { temperatures are lower. }\end{array}$ & $\begin{array}{l}\text { Mean temperature from } \\
\text { April } 1 \text { of capture year } \\
\text { until date of capture } \\
\text { (DAYMET; Thornton et } \\
\text { al. 2020) }\end{array}$ \\
\hline Heat Mortality & $\begin{array}{l}\text { Because larger individuals tend } \\
\text { to have lower critical thermal } \\
\text { maxima, individuals will be } \\
\text { smaller in areas where } \\
\text { maximum temperatures are } \\
\text { higher. }\end{array}$ & $\begin{array}{l}\text { Mean annual maximum } \\
\text { temperature (1980- } \\
\text { 2010; DAYMET; } \\
\text { Thornton et al. 2020) }\end{array}$ & $\begin{array}{l}\text { Because larger individuals tend } \\
\text { to have lower critical thermal } \\
\text { maxima, individuals will be } \\
\text { smaller after years in which } \\
\text { maximum temperatures are } \\
\text { higher. }\end{array}$ & $\begin{array}{l}\text { Maximum temperature } \\
\text { in the preceding } 365 \\
\text { days (DAYMET; } \\
\text { Thornton et al. 2020) }\end{array}$ \\
\hline Resource Availability & $\begin{array}{l}\text { Because individuals living in } \\
\text { more productive environments } \\
\text { tend to be larger, individuals } \\
\text { will be larger in areas where } \\
\text { primary productivity is higher. }\end{array}$ & $\begin{array}{l}\text { Net primary productivity } \\
\text { during April - October } \\
\text { (2000-2016; MODIS; } \\
\text { Stockli 2020) }\end{array}$ & $\begin{array}{l}\text { Because individuals living in } \\
\text { more productive environments } \\
\text { tend to be larger, individuals } \\
\text { will be larger after years in } \\
\text { which primary productivity is } \\
\text { higher. }\end{array}$ & $\begin{array}{l}\text { Net primary productivity } \\
\text { in months preceding } \\
\text { capture, inclusive of } \\
\text { month of capture } \\
\text { (MODIS; Stockli 2020) }\end{array}$ \\
\hline Starvation Resistance & $\begin{array}{l}\text { Because larger body size } \\
\text { increases an individual's ability } \\
\text { to survive periods of resource } \\
\text { scarcity, individuals will be } \\
\text { larger in areas where periods } \\
\text { of resource scarcity (e.g., } \\
\text { winters) are most severe. }\end{array}$ & $\begin{array}{l}\text { Average minimum } \\
\text { temperature in April, } \\
\text { May, September, and } \\
\text { October (1970-2000; } \\
\text { WorldClim; Fick and } \\
\text { Hijmans 2017) }\end{array}$ & $\begin{array}{l}\text { Because larger body size } \\
\text { increases an individual's ability } \\
\text { to survive periods of resource } \\
\text { scarcity, individuals will be } \\
\text { larger after years in which } \\
\text { periods of resource scarcity } \\
\text { (e.g., winters) are most severe. }\end{array}$ & $\begin{array}{l}\text { Average minimum } \\
\text { temperature in the April, } \\
\text { May, September, and } \\
\text { October preceding } \\
\text { capture (DAYMET; } \\
\text { Thornton et al. 2020) }\end{array}$ \\
\hline
\end{tabular}



along a $>30^{\circ}$ gradient in latitude.

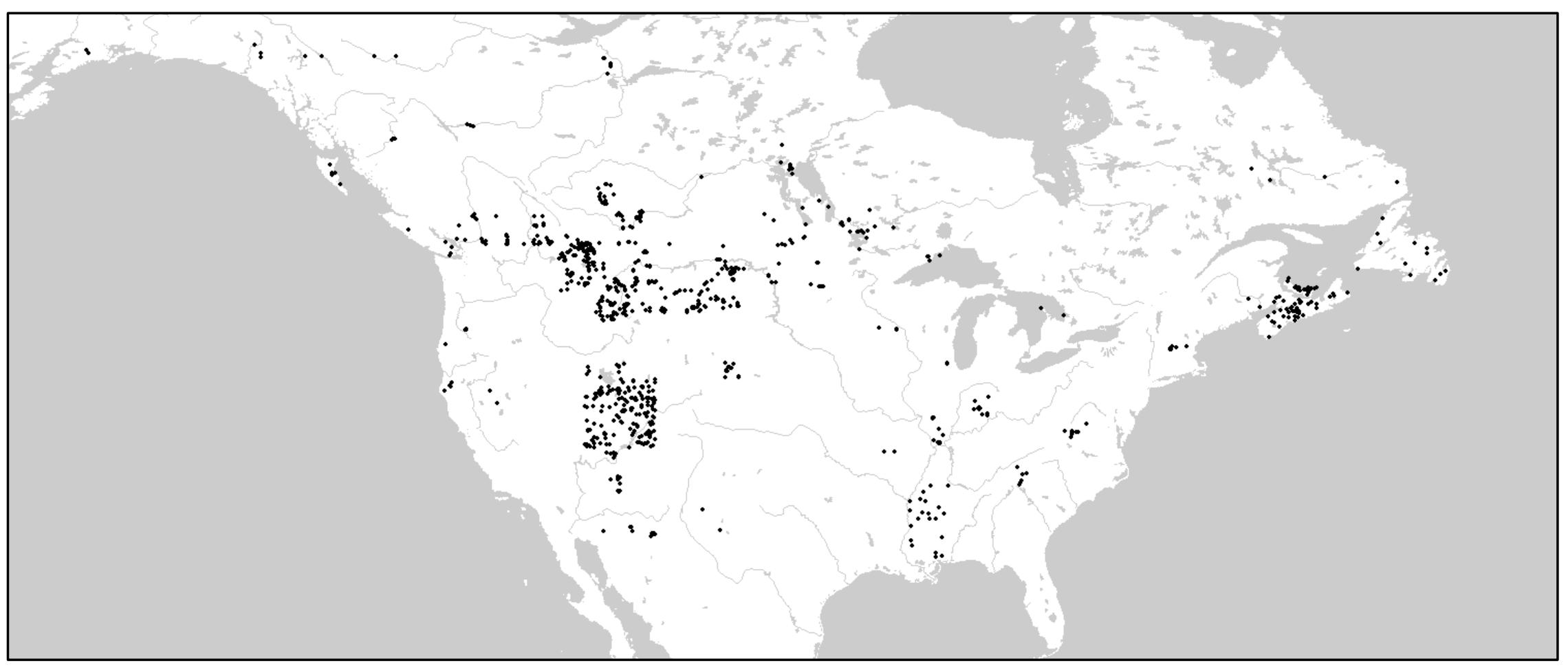


Fig. 2. Intraspecific patterns in body mass across space in 20 species of North American bats, which most strongly support the heat

629 conservation hypothesis. In the left column, we plotted the regression coefficient (slope) for each species' relationship between body mass and the predictor variable of interest (points) and $90 \%$ credible intervals (lines). Points above the dotted line at 0 indicate species in which individual body mass increased as the variable of interest (A. Mean annual temperature; B. Maximum annual temperature; C. Autumn/spring temperature; D. Net primary productivity) increased. Species are ordered from largest (left) to smallest (right) sample sizes. In the right column, we plotted histograms of the coefficients. Row A represents tests of the heat conservation hypothesis, Row B represents tests of the heat mortality hypothesis, Row C represents tests of the resource availability hypothesis, and Row D represents tests of the starvation resistance hypothesis. Distributions centered on zero indicate no consistent effect of the variable of interest on body mass, while distributions centered asymmetrically around zero indicate directional effects. Credible intervals were truncated at the limit of the y-axis for ease of interpretation. The mean estimate of the coefficient for the effect of net primary productivity on body mass for Myotis leibii (MYLE; 4.29) was excluded from the y-axis of that graph to improve interpretability of coefficient estimates for the other species, but the $90 \%$ credible interval for that estimate crosses zero as shown in the graph. Species codes are listed in Table A1. 

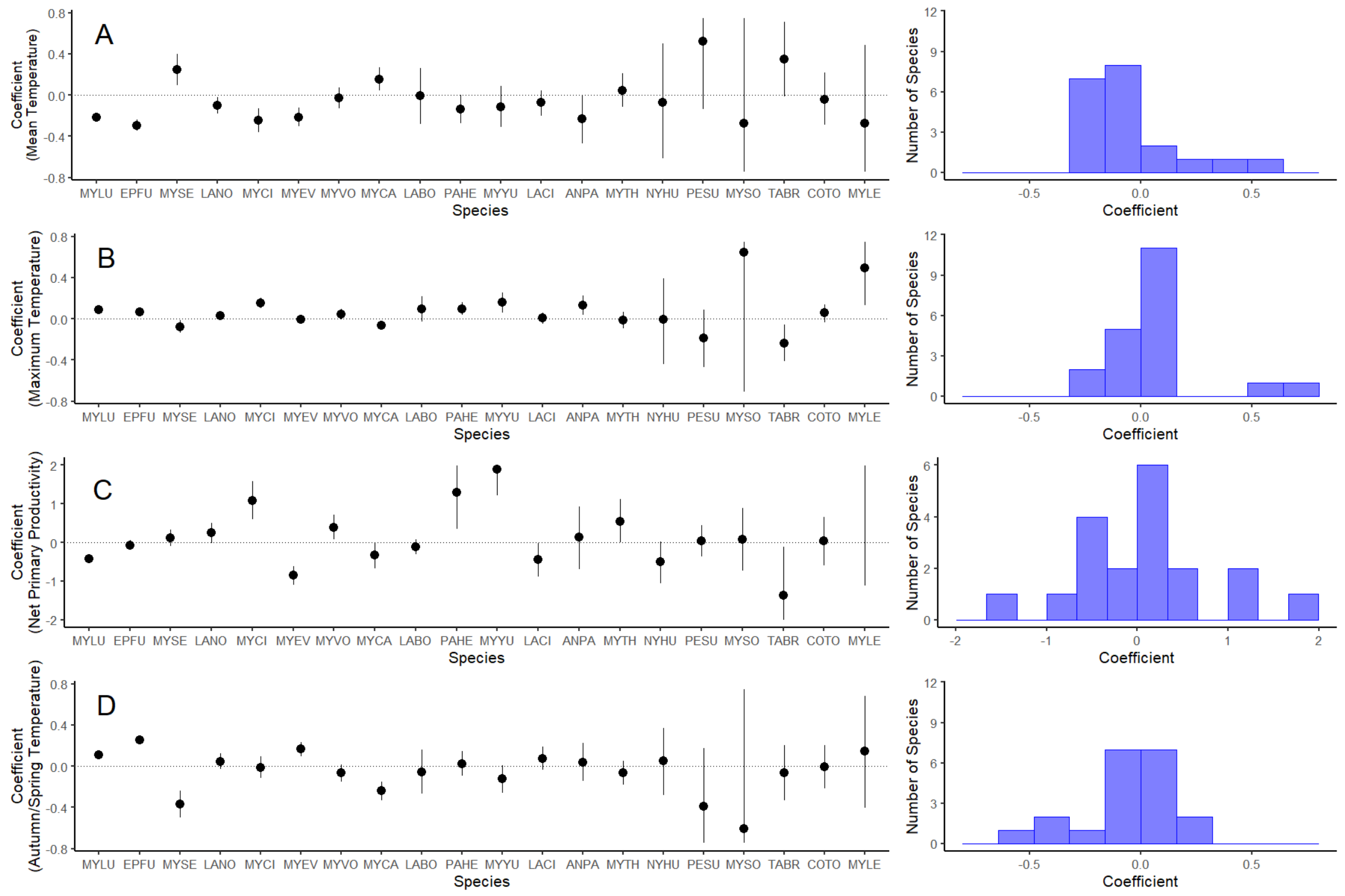
Fig. 3. Intraspecific patterns in body mass across time in 20 species of North American bats, which most strongly support the resource

644 availability hypothesis. In the left column, we plotted the regression coefficient (slope) for each species' relationship between body

645 mass and the predictor variable of interest (points) and 90\% credible intervals (lines). Points above the dotted line at 0 indicate species

646 with larger masses as the variable of interest (A. Mean annual temperature; B. Maximum annual temperature; C. Autumn/spring

647 temperature; D. Net primary productivity) increased. Species are ordered from largest (left) to smallest (right) sample sizes. In the

648 right column, we plotted histograms of the coefficients. Row A represents tests of the heat conservation hypothesis, Row B represents

649 tests of the heat mortality hypothesis, Row C represents tests of the resource availability hypothesis, and Row D represents tests of the

650 starvation resistance hypothesis. Distributions centered on zero indicate no consistent effect of the variable of interest on body mass,

651 while distributions centered asymmetrically around zero indicate consistent effects. Credible intervals were truncated at the limit of

652 the y-axis for ease of interpretation. Species codes are listed in Table A1. 

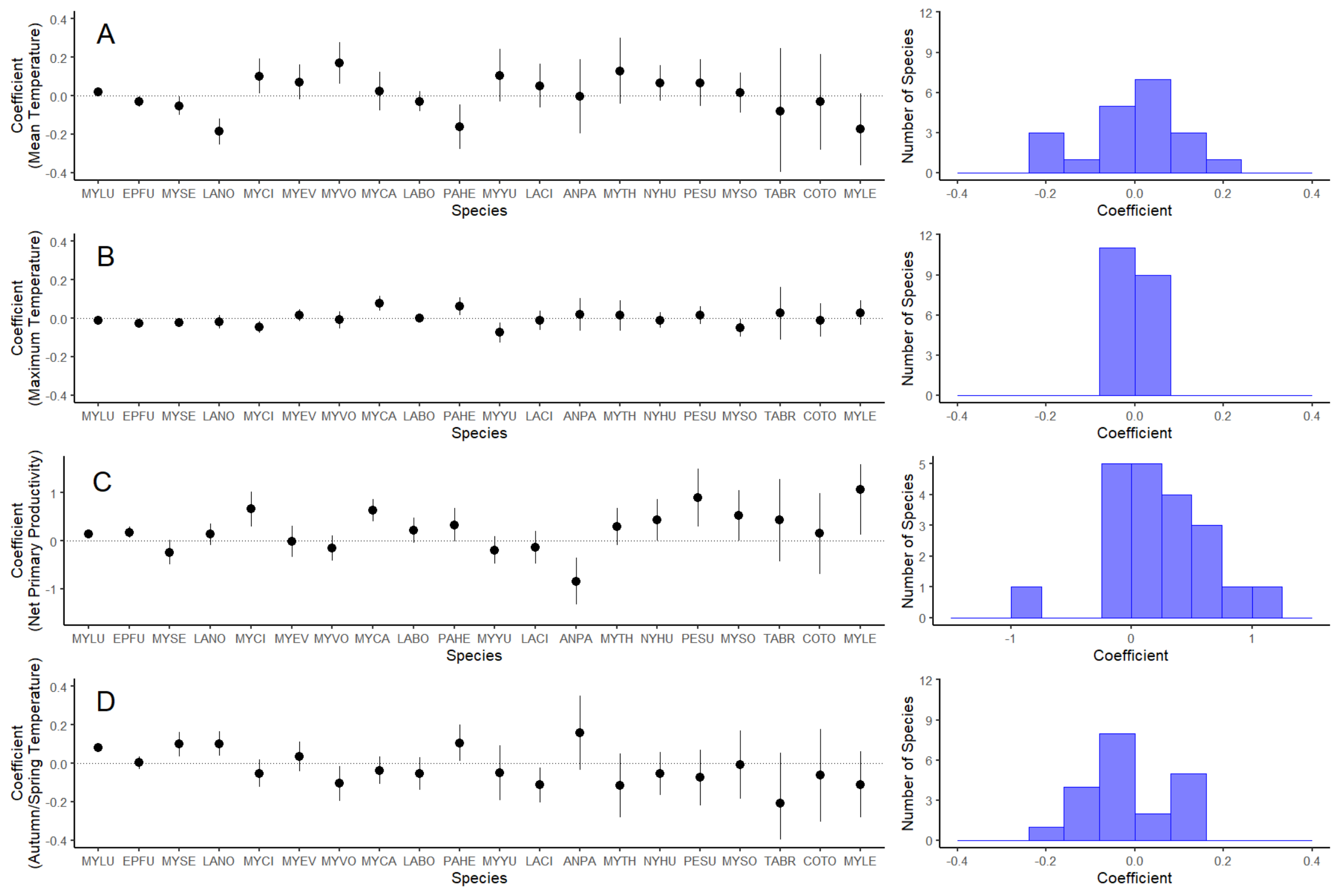
656 Table A1. Table including species included in our analysis, species code (used in figures), the number of individuals included in each

657 species' model, the latitudinal range covered by individuals of each species (in degrees), and the number of distinct site-year

658 combinations at which each species was captured.

\begin{tabular}{llrrr}
\hline Species & Species Code & Number of Individuals & Latitudinal Range & Number of Site-years \\
\hline Antrozous pallidus & ANPA & 567 & 17.50 & 136 \\
Corynorhinus townsendii & COTO & 234 & 18.32 & 92 \\
Eptesicus fuscus & EPFU & 4,123 & 28.29 & 551 \\
Lasiurus borealis & LABO & 918 & 18.55 & 132 \\
Lasiurus cinereus & LACI & 824 & 20.82 & 236 \\
Lasionycteris noctivagans & LANO & 1,572 & 20.73 & 300 \\
Myotis californicus & MYCA & 1,183 & 21.98 & 212 \\
Myotis ciliolabrum & MYCI & 1,540 & 20.07 & 318 \\
Myotis evotis & MYEV & 1,353 & 21.17 & 384 \\
Myotis leibii & MYLE & 150 & 8.11 & 67 \\
Myotis lucifugus & MYLU & 12,293 & 23.53 & 693 \\
Myotis septentrionalis & MYSE & 1,702 & 25.39 & 243 \\
Myotis sodalis & MYSO & 285 & 2.54 & 48 \\
Myotis thysanodes & MYTH & 495 & 18.90 & 159 \\
Myotis volans & MYVO & 1,309 & 24.38 & 307 \\
Myotis yumanensis & MYYU & 847 & 18.24 & 136 \\
Nycticeius humeralis & NYHU & 403 & 13.59 & 59 \\
Parastrellus hesperus & PAHE & 905 & 8.73 & 86 \\
Perimyotis subflavans & PESU & 339 & 14.50 & 59 \\
Tadarida brasiliensis & TABR & 261 & 10.50 & \\
\hline
\end{tabular}


Fig. A1. Graphical representation of an individual model. In each model, standardized body mass is a function of the four proxies for

661 the spatial hypotheses, the four proxies for the temporal hypotheses, and random intercepts for each data provider (to account for

662 known differences in protocols for weighing bats). This approach allows tests for the relative contribution of each hypothesis in

663 shaping body size while accounting for the others. In the event that multiple factors interact to influence body size, this approach also

664 allows detection of contributions to body size from multiple hypotheses simultaneously.

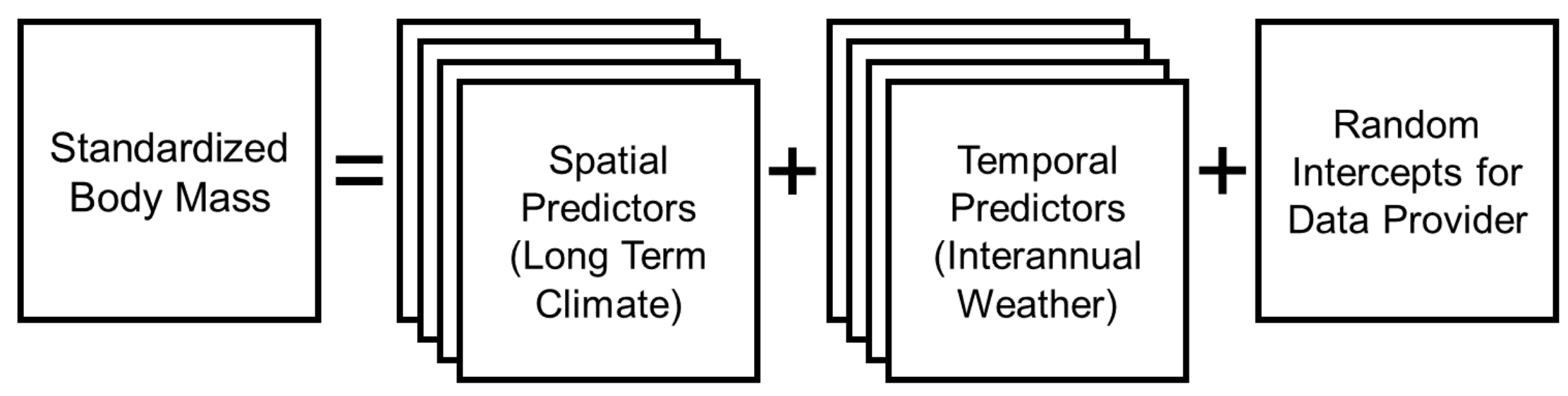


Fig. A2. Intraspecific patterns in body mass across latitude and year in 20 species of North American bats. In the left column, we
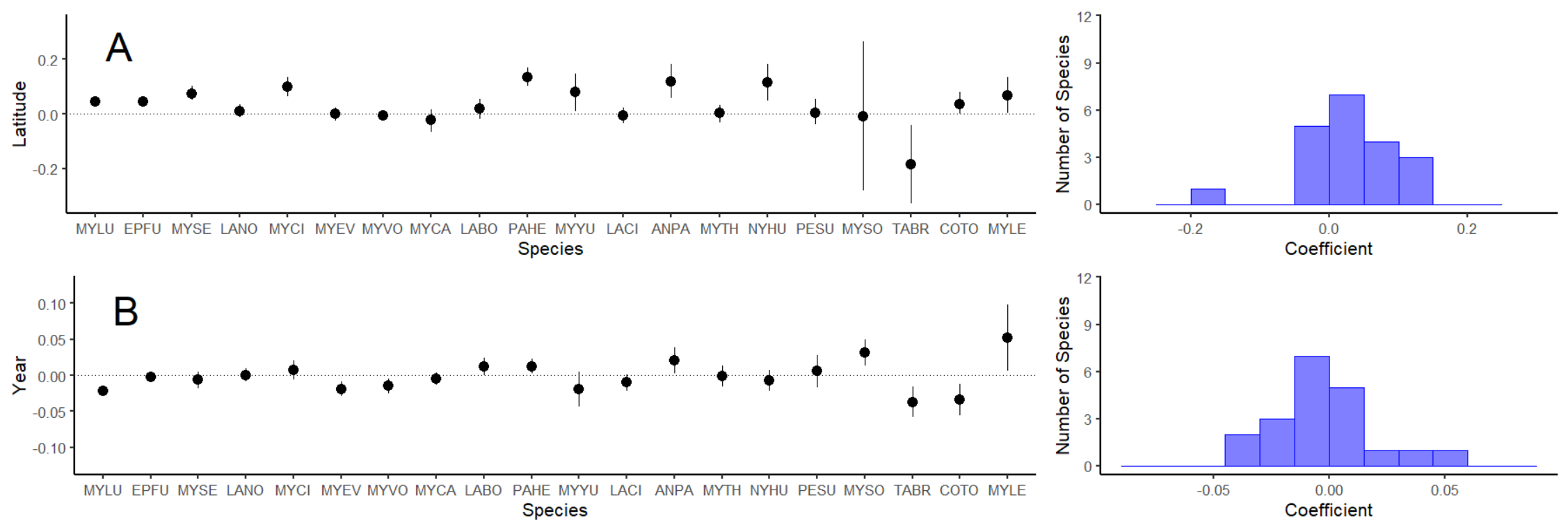
673 Fig. A3. Scatterplots depicting relationships between latitude and variables of interest (left

674 column), and year and variables of interest (right column). Each point represents one capture

675 location, trend lines represent a linear regression of the trend across space or time, and the color

676 of the points represents the number of bats captured at a location (darker points denote more

677 captures). Confidence intervals (95\%) are represented by gray ribbons (which are very narrow in

678 all regressions due to large sample sizes). Contrary to expectations, net primary productivity at

679 capture sites increased at higher latitudes (due in part to a large number of bats captured in the

680 arid southwestern United States where primary productivity is low, and the exclusion of winter

681 months when primary productivity is much lower at more northern sites). Following

682 expectations, mean annual temperatures, maximum temperatures, and spring and autumn

683 temperatures decreased as latitude increased. If body size is driven by any of these predictor

684 variables, geographic variation in each of these predictor variables (or some combination

685 thereof) could create a spatial pattern of body mass consistent with Bergmann's Rule. Across

686 time during our study period, spring and autumn temperatures and net primary productivity

687 increased, while mean annual temperatures and maximum temperatures were relatively constant.

688 Consequently, only spring and autumn temperatures and net primary productivity could lead to

689 an observed trend of shrinking body mass over time during our study. Nevertheless, interannual

690 variation in each of these variables was substantial, so if any of these predictor variables are

691 initiating rapid evolutionary change in body size, our analyses are likely to detect it. 

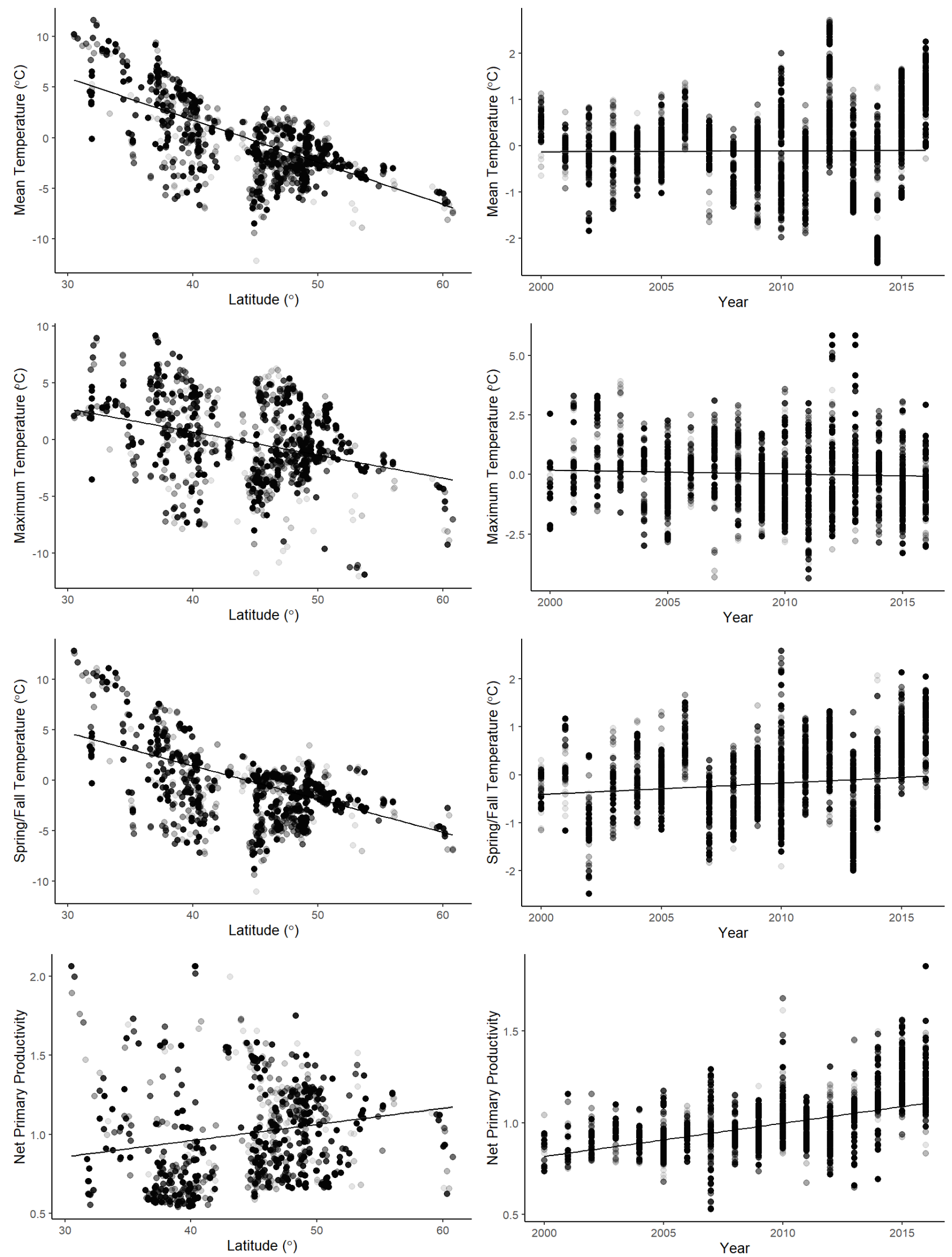